\title{
Environmental Professional's Perception of the Usefulness of Knowledge and Awareness of Climate Change
}

\author{
Adekunle Olatumile PhD. \\ Department of Arts Education \\ Adekunle Ajasin University, Akungba-Akoko \\ E-mail: kunletumile@yahoo.com
}

\section{Doi:10.5901/jesr.2013.v4n3p61}

\begin{abstract}
Climate change is at the forefront of discourse in the 21 st century, which is assuming alarming dimensions year in year out. Climate change specialists have repeatedly pointed out that a solution to climate change problem will require climate change awareness and its proper understanding. This requires the concerted effort of climate change extension agents who will ensure that the necessary attitudinal change required for positive climate change behaviour is achieved. In spite of the attention climate change has attracted lately and the attendant general debate, the relevance of environmental professionals in mitigating climate change and in climate change extension remains comparatively unexplored issue especially in the realm of policy making. The study assessed environmental professional's perception on the usefulness of awareness and knowledge of climate change. One hundred and ten environmental professionals were selected. A structured questionnaire was used to collect data. Knowledge and awareness of climate change is potentially helpful to the environmental professionals personally and in climate change extension. Gender did not significantly determine opinion on the usefulness of knowledge and awareness of climate change. Climate change education should be delivered along lifelong learning approach. Environmental professionals should be exposed to regular in-service and on the job training on climate change issues. They should be adequately groomed in andragogical skills
\end{abstract}

\section{Introduction}

The new millennium is in its early stage, within a little about a decade, there have been the occurrences of some of the most appalling natural disasters ever witnessed by humanity. These devastating events point to the vulnerability of humans to natural hazards. There cannot be serious doubt that the earth's climate is changing and changing at a pace that has caught many unprepared. Climate change is the significant change in weather (wind, precipitation and temperature) over an extended period of time. The least developed countries-a group of forty-eight of the poorest developing countries located in Africa and Asia- seem to be at the receiving end of the effects of climate change. This is borne out of the fact that these nations lack the necessary institutions and infrastructural facilities that can facilitate mitigation and adaptation to the consequences of climate change. Current predictions suggest that natural hazardsmany of which will be climate-related are expected to increase both in scale, frequency and severity in the coming decades, affecting many different parts of the globe, but affecting some regions worse than others (Ouskainen, 2008). Climate change phenomenon is assuming alarming dimensions year in year out. The impacts are becoming more visible in every part of the globe. There are incidences of increased number of floods, droughts, storms, ocean incursion and heat waves. As a matter of fact, climate change threatens the basic systems on which we all depend (Moench, 2011). The impacts are also with us, affecting each and every one disproportionately, thus, Moench (2011) averred that its impact will vary across economic and social contexts. He argued further that marginalised groups- the poor, women, children, and those who for political, cultural, religious or ethnic reasons lack access to capacity and resources- are particularly vulnerable to the impacts of climate change.

Public risk perception plays a key role in shaping natural hazards policy and management response system (Slovic, 2000) and given the fact that the regulation and management of risks such as extreme weather events, are subject to public debate and input, perception of these risks are of considerable interest to local planners and policy makers ( Fischhoff; Lichtestein; Slovic; Derby \& Keeey 1981, Johnson \& Tverskey, 1993 cited in Brody, Zahran \& Grover, 2008). While useful, public opinion polls have limited utility for explaining public risk perceptions of global climate change. Most polls use only relatively simple, holistic measures of concern (e.g., "how serious of a threat is global warming"), which provide little insight into the determinants and components of public risk perception (Leiserowit, 2006). For example, a critical finding of recent research on risk perception is that public perceptions are influenced not only by 
scientific and technical descriptions of danger, but also by a variety of psychological and social factors, including personal experience, affect and emotion, imagery, trust, values and world views - dimensions of risk perception that are rarely examined by opinion polls (Slovic, 2000 cited in Leiserowit, 2006).

It has been observed that individuals who regard themselves as capable of positively affecting climate change, as well as influencing others in their social network to behave in ways that mitigate the problems, are significantly more likely to regard the risk more seriously and take corrective actions (Bordetal 1998; O'Connor et al. 1999 \& Savage 1993 cited in Brody, Zahran \& Grover, 2008). On the risk of climate change, researchers found that public literacy on the properties, causes and likely effects of the global climate change is low (Henry, 2000) Researchers also found out that persons with pro-environmental attitudes were significantly more willing to support risk reduction efforts related to greenhouse gas emission.... similarly, persons who regarded the bio-physical world as 'fragile' were more likely to adopt behaviours and support policies that mitigate the risks of climate change. Thus, responding with a stronger set of ecological values will perceive a greater risk associated with global climate change (Bordetal 1998; O'Connor et al. 1999 \& Savage 1993 cited in Brody, Zahran \& Grover, 2008) . It is thus expected that persons with higher perceived personal efficacy are more likely to define climate change as risky (Brody, Zahran \& Grover, 2008) .Several authors note that perception about environmental and natural resources differ for individuals, since their perceived world is subjectively constructed and is influenced by previous experience, type of education, and other socio-economic characteristics (Sudamardi et al. 2001; Filip et al 1983 Feijoo \& Momo 1991 quoted by Otto-Banaszak, Matczaki, Wessclar and Wechsung 2010). Traditionally, natural hazards risk perception has been explained by factors such as prior experience, knowledge, socio-economic and demographic characteristics and household composition (Brody, Zahran \& Grover, 2008).

\section{Import of Climate Change Knowledge and Awareness}

Climate awareness is manifested through familiarity with perception about, and intuitive knowledge about climatic events (Saroar, and Routray, 2010). Climate Change awareness according to Ekpo and Ekpo (2011) involves creating knowledge, understanding and values, attitudes, skills and abilities among individuals and social groups towards the issue of climate change for attaining a better quality environment. Climate change specialists have repeatedly pointed out that a solution to climate change problem will require climate change awareness and its proper understanding (Ekpo \& Ekpo, 2011). This requires the concerted effort of climate change extension agents who will ensure that the necessary attitudinal change required for positive climate change behaviour is achieved. If the popular maxim that you cannot give what you do not have is a truism, then it becomes incumbent on environmental professionals to wear the toga of object of identification. Kollmuss and Agyeman (2002) perused literature and found the following variables associated with responsible pro-environmental behaviour

- Knowledge of issues: The person has to be familiar with the environmental problem and its causes

- Knowledge of action strategies: The person has to know how he or she has to act to lower his or her impact on the environmental problem

- Locus of control: This represents an individuals' perception of whether he or she has the ability to bring about change

Climate change has constituted one of the most embarrassing environmental threats and has manifested a wide range of implications for all and sundry including environmental professionals who are supposed to be extension agents that should provide direction on climate change mitigation.

As evidence of climate change and its impact continue to gain momentum, it has become clear that many of the causes of climate change are anthropogenic in nature through lifestyles, consumption and choices that pollute and exploit resources in an unsustainable manner. The future health hazards of climate change are well documented, with forecasts made of increasing health problems caused by heat waves, droughts and infectious diseases. It also predicted that climate change will have detrimental effects on agriculture and fisheries and may even result in collapsing ecosystems (Pande and Rau, 2011).

Nigeria as a developing nation is particularly sensitive to the effects of climate change. A large part of the economy of the country depends on natural resources, which are particularly vulnerable to climate change. When the resources are affected, communities are implicated. Disease, loss of livelihoods and settlement can force entire communities into complete extinction and even refugee status. As critical as the effect of climate change is, it is not clear whether Nigerians are aware of what climate change is is or its effects (Jekayinfa \&Yusuf, 2012). Lack of information (awareness) and knowledge (education) about climate change also mean that many Nigerians are reluctant to accept the 
reality of climate change. There is lack of public policy, government preparedness and commitment to promoting climate change adaptation strategies in the country. Jekayinfa and Yusuf (2012), DFID (2011) opined that the complex and uncertain nature of climate change requires the application of a range of skills across many sectors and professions for climate change adaptation and mitigation processes... the required competencies reflect the multi-disciplinary nature of climate change. Climate advisers will however need to demonstrate in depth understanding of a number of the areas, and a broad understanding of several others, and through continuing professional development further strengthen both the depth and breadth of their knowledge. Aquah (2011) argued that climate change is a multi-faceted challenge for today's societies through its impacts on human lives and the natural environment; he averred that climate change is a critical issue and strongly recommended that awareness and quality of knowledge on existence and issues relating to climate change could reduce the impacts of the phenomenon.

\section{Statement of the Problem}

Climate change induced extreme weather events occasioned by rising global temperatures keep increasing in terms of frequency and impact. Scientific predictions have indicated that the coming years will witness more intense climate change related natural hazards such as floods, ocean surge, droughts, floods, heat- waves, storms and so on. Society will have to make decisions in the coming years about how to adapt to a changing climate. Climate variability and climate change create risks to all sectors of the economy. Climate is already a prime factor in nine out of ten disasters, many of which cost billions of dollars and thousands of lives. Effective preparation for the possible effects of climate change requires the engagement of resource managers, planners, public works officials, local managers, community development specialists, businesses, residents, and property owners. The challenge is to provide these diverse stakeholders with trusted, useful, science-based information so that they in turn can make informed decision (www.seclimate.org). Some studies focused on the perception of climate change risks, however there is little known about the perception of climate change adaptation among stakeholders (Otto-Banaszak, Matczaki, Wessclar and Wechsung 2010). These include climate change professionals whose primary duty is to provide enlightenment on climate change.

\section{Purpose of the Study}

The general purpose of the study is to carry out assessment of environmental professionals' perception of the usefulness of awareness and knowledge of climate change. Specifically the study is set to ascertain environmental professional's opinion on the usefulness of knowledge and awareness of climate change and to determine whether socio-demographic characteristics will significantly determine environmental professional's opinion on the usefulness of knowledge and awareness of climate change

\section{Population}

The population of the study is environmental professionals in Ondo State, Nigeria. These are people who are engaged in professions that relate to environmental management and protection. They include Environmental Health officers, Forest Guards, Water and Sanitation workers and waste Management Workers.

\section{Sample and Sample Techniques}

The sample comprised one hundred and ten environmental professionals selected through multistage sampling technique.

Stratified sampling technique was used to divide the sample along professional leaning,

Environmental Health Officers $\quad 40$

Forest Guards 30

Water and Sanitation Workers $\quad 25$

Waste Management Officers 25

Proportionate sampling technique was used to determine selectable elements based on socio-demographic characteristics

Accidental random technique was used to select individual sample elements that constituted the respondents. 


\section{Instrumentation}

The instrument for data collection is a questionnaire comprising two sections, section A contains socio-demographic characteristics of respondents, section B consists of questions on usefulness of awareness and knowledge of climate change. The instrument was administered through three trained research enumerators who contacted the respondents in their various places of work. One hundred and thirty questionnaires were administered out of which one hundred and ten properly filled were used for the study.

\section{Validity}

The instrument was subjected to face validity. It was given to experts in the Departments of Guidance and Counseling, Science and Technical Education and Adult Education. They made their input before the instrument was finally used for the study.

\section{Reliability}

The instrument was pilot tested on twenty subjects who were not part of the sample and the administered instruments were divided into two equal half. The two sets of questionnaire were correlated using Pearson Product Moment Correlation. The reliability coefficient of 0.78 was obtained.

\section{Data Analysis}

Data were analysed using frequency counts, percentage and chi-square.

\section{Research Question}

What is environmental professional's perception of the usefulness of knowledge and awareness of climate change?

Table 1: Environmental professional's opinion on the usefulness of knowledge and awareness of climate change

\begin{tabular}{|c|l|c|c|c|c|}
\hline & \multicolumn{1}{|c|}{ Agree } & \multicolumn{2}{c|}{ Disagree } \\
\hline S/N & \multicolumn{1}{|c|}{ Question } & Response & Percentage & Response & Percentage \\
\hline 1 & It will be helpful in meeting my own information needs & 90 & 82 & 20 & 18 \\
\hline 2 & It will be helpful in influencing my life style & 64 & 55 & 46 & 45 \\
\hline 3 & It will be helpful when I try to find a job & 53 & 48 & 57 & 52 \\
\hline 4 & It will give me a better understanding of the world & 69 & 63 & 41 & 37 \\
\hline 5 & $\begin{array}{l}\text { It will be helpful in creating awareness about } \\
\text { environmental issue by enlightening many on the } \\
\text { challenges posed by illegal waste disposal }\end{array}$ & 75 & 68 & 35 & 32 \\
\hline 6 & $\begin{array}{l}\text { It will be help me to know that we are in a period of } \\
\text { climate change }\end{array}$ & 96 & 87 & 14 & 13 \\
\hline 7 & $\begin{array}{l}\text { It will enable me to realize that human activities cause } \\
\text { climate change }\end{array}$ & 60 & 55 & 50 & 45 \\
\hline 8 & $\begin{array}{l}\text { It will enable me to know that climate change is not } \\
\text { only caused by natural occurrence only, but also by } \\
\text { human activities }\end{array}$ & 85 & 77 & 25 & 23 \\
\hline
\end{tabular}

The table above shows environmental professional's perception of the usefulness of knowledge and awareness of climate change. $82 \%$ responded that it will be helpful in meeting their information needs. $55 \%$ opined that it will be helpful in influencing their life style. $57 \%$ disagreed that it will be helpful when trying to find a job. $63 \%$ agreed that it will It will give them a better understanding of the world. $68 \%$ were of the opinion that it will help them in creating awareness about environmental issue by enlightening many on the challenges posed by illegal waste disposal. $87 \%$ claimed that it will help them to know that we are in a period of climate change. $55 \%$ believed that it will enable them to realize that human activities cause climate change. $77 \%$ agreed that it will enable them to know that climate change is not caused by 
natural occurrence, but also by human activities. Ekpo and Ekpo (2011) have found that Climate change specialists have repeatedly pointed out that a solution to climate change problem will require climate change awareness and its proper understanding. The analysis above shows that knowledge and awareness of climate change is potentially beneficial to environmental professionals, for instance knowing fully well the import of climate change in the discharge of their duties, they are now constrained to seek for information in this regard, in the process of doing this, they become informed in other areas and as such their information needs in different aspect of human endavours. For example women in the process come across family planning information; men may come across pre-retirement and retirement vocational skills. The lifestyles of the environmental professionals are also influenced, for instance their consumption patterns may become modified; because of the fact that they are extension agents ,they may want to play the role of object of identification by exhibiting sustainable positive environmental behaviour. They may refuse to buy non climate change compliant products like refrigerators that are not chlorofluorocarbon (CFC) free, products that are not made from recycled materials and so on. Knowledge and awareness of climate change will imbue environmental professionals with a sense of understanding the world better as the study of climate change requires a reasonable level of understanding of the biophysical structure of the universe as well as the effects of human interaction with natural resources. Environmental professionals are confronted with the reality of climate change in spite of the scientific arguments and counter arguments concerning the reality and causes of climate change, as this will now better equip them to perform their extension services in creating such awareness in other people and bringing about positive climate change attitude in their clienteles. They will by so doing effect some change in the activities of human beings that instigate climate change, for example they will be able to convince people on the need for reduction in carbon emission and other anthropogenic greenhouse gases. Majority of the respondents (57\%) are not aware of the effect of climate change on job, This negates the finding of European Commission where European Union citizens expressed a positive view of the economic benefits of tackling climate change - almost eight in ten (78\%) respondents agreed that fighting climate change and using energy more efficiently can boost the economy and create jobs. This may be due to the fact that they are considering white collar jobs. Environmental professional are supposed to be well acquainted with what implications climate change will exert on peoples job and livelihoods. Such knowledge will influence the type of job the respondents are likely to undertake or the jobs they will advise that people undertake and how to mainstream climate change challenges in these jobs, for instance farmers are vulnerable to climate change hence they may be advised to venture into alternative and complementary vocations that may likely cushion or mitigate the effects of climate on their primary vocation. Sometimes the effects of climate change may be catastrophic to the extent that they may result in mass loss of jobs; in that case they will prepare people to mitigate this by venturing into alternative vocations as this will constitute part of the contents of their extension messages. Their awareness in this regard is low and it shows a gap in the discharge of their profession as far as climate change extension is concerned.

\section{Hypothesis}

Gender will not significantly determine environmental professional's perception of the usefulness of knowledge and awareness of climate change

Table 2: Chi-square test showing the summary of influence of gender on environmental professionals' perception of the usefulness and awareness of climate change.

\begin{tabular}{|c|c|c|c|c|c|c|c|c|}
\hline & $\begin{array}{c}\text { It will be } \\
\text { helpful in } \\
\text { meeting } \\
\text { my own } \\
\text { information } \\
\text { needs }\end{array}$ & $\begin{array}{c}\text { It will be } \\
\text { helpful in } \\
\text { influencing } \\
\text { my life } \\
\text { style }\end{array}$ & $\begin{array}{c}\text { It will be } \\
\text { helpful } \\
\text { when I try } \\
\text { to find a } \\
\text { job }\end{array}$ & $\begin{array}{c}\text { It will give me } \\
\text { a better } \\
\text { understanding } \\
\text { of the world }\end{array}$ & $\begin{array}{c}\text { It will be helpful in } \\
\text { creating awareness } \\
\text { about environmental } \\
\text { issue by enlightening } \\
\text { many on the } \\
\text { challenges posed by } \\
\text { illegal waste disposal }\end{array}$ & $\begin{array}{c}\text { It will help me } \\
\text { to know that } \\
\text { we are in a } \\
\text { period of } \\
\text { climate } \\
\text { change }\end{array}$ & $\begin{array}{c}\text { It will enable to realize } \\
\text { me } \\
\text { that human } \\
\text { activities } \\
\text { cause climate } \\
\text { change }\end{array}$ & $\begin{array}{c}\text { It will enable me } \\
\text { to know that } \\
\text { climate change is } \\
\text { not only caused } \\
\text { by natural } \\
\text { occurrence only, } \\
\text { but also by } \\
\text { human activities }\end{array}$ \\
\hline Chi-square & 49.200 & 19.891 & 2.509 & 15.309 & 18.800 & 62.291 & 2.727 & 44.255 \\
\hline df & 3 & 3 & 3 & 3 & 3 & 3 & 3 & 3 \\
\hline $\begin{array}{c}\text { Level of } \\
\text { significance }\end{array}$ & .000 & .000 & .474 & .002 & .000 & .000 & .436 & .000 \\
\hline
\end{tabular}


There is no cell that had expected frequencies less than 5 . The $\mathrm{df}=(3)$ and the significance level for 2-tailed was 0.05 . The $x^{2}$ value is significant because the value under the significance column is less than 0.05 and chi-square value. The result indicates that, age and gender did not significantly determine environmental professional's perception of the usefulness of knowledge and awareness of climate change. Therefore the null hypothesis is upheld. Though the $x^{2}$ indicates that, it will enable the respondents to realize that human activities do contribute to the phenomenon of climate change and it will not be helpful when trying to find a job. From the analysis above it can be inferred that climate change is a phenomenon that assumes global dimension and that cuts across all strata of the society, even though it affects regions, communities and different strata of the society disproportionately, no segment of the society can lay claim to immunity from sharing out of the effects of climate change. As men are affected so also are women; as the young are affected so also are the aged and elderly. Professional leaning does not preclude people from being affected by the consequences of climate change. The $x^{2}$ also indicates that gender and age significantly determined environmental professionals' response that climate change will not be helpful when finding a job. The implication is that environmental professional' knowledge of climate change will not influence the type of job the respondents are likely to undertake or advice that people undertake; Their awareness in this regard is low and it shows a gap in the discharge of their profession as far as climate change extension is concerned. This confirms the finding of Skinner (2010) that women and men do not experience climate change equally. In many developing countries economic constraints and cultural norms that restrict women's access to paid employment mean that their livelihoods are particularly dependent on climatesensitive sectors, such as subsistence agriculture or water collection. Yet gender inequalities in the distribution of assets and opportunities mean their choices are severely constrained in the face of climate change. For example, restrictions around land ownership for rural women mean they may not have access to productive land to farm, and lack of financial capital means with which they can easily diversify their livelihoods. Care www.careclimatechange.org found that majority of the world's poorest people today is women and girls. Climate change is making it even more difficult for them to realise their basic rights, and it is exacerbating inequalities since they are more vulnerable to its impacts than men. Moreover, many women are denied access to new information about climate change and participation in important decision-making processes despite having unique skills and knowledge - about low risk farming, sustainable water management, family health and community mobilisation, for example - vital to effective adaptation. For all these reasons, and because women are central to the food and livelihood security of their families, there is need to place a special emphasis on gender equality and women's empowerment. From the foregoing responsible climate change behaviour, can only be realized when women and men have an equal voice in decision-making on climate change and broader governance processes and are given equal access to the resources necessary to respond to the negative effects of climate change; where both women's and men's needs and knowledge are taken into account and climate change policymaking institutions and processes at all levels are not biased towards men or women; and where the broad social constraints that limit women's access to strategic and practical resources no longer exist (Skinner, 2011).

\section{Recommendations}

Environmental Professionals knowledge and awareness of climate change should be further reinforced through the following strategies : :

They should be exposed to media that disseminate and share climate change related information and knowledge. These include climate change publications, e-newsletters, discussion forums, web-sites, audio-visuals like television; home video, radio.

The potent power of mass media in information dissemination and knowledge creation should be optimally harnessed in keeping environmental professionals updated on causes, adaptation and mitigating the effects of climate change. Programmes in this direction should be regularly aired in English, pidgin and local languages.

Environmental professionals should be exposed to workshops, trainings, seminars and conferences on climate change both home and abroad.

The curriculum of some of these professions are not attuned to climate change reality, hence the shallow knowledge of graduates produced, climate change issues must be adequately mainstreamed into these curriculum so that graduates will be adequately equipped to play their roles as climate change extension agents.

International agencies and Non-Governmental Organisations whose scopes fall within climate change related issues, should target environmental professionals in their activities. 
Universities and other institutions of higher learning should in the discharge of their town and gown duties carry out researches and projects on climate change in collaboration with environmental professionals since they are in a better position to carry out actual implementation on the field.

Government, Civil Society Organisations, Non-governmental Organisations, Media Organisations should provide Environmental professionals with the necessary skills and empowerment to;

Promote climate change extension beyond purely technical analyses to a focus on the social and gender dimensions.

Possess ability to mainstream gender sensitive climate change interventions and processes in policy, research, grassroots programmes or advocacy.

Promote a rights-based approach to climate change and ensure that all future climate change policies and processes draw on human rights frameworks such as the Convention on the Elimination of all Forms of Discrimination against Women (CEDAW).

Address the underlying causes of gender inequality, by tackling issues such as unequal land rights through legislative reforms and awareness-raising, as well as through the implementation of Convention on the Elimination of all Forms of Discrimination against Women (CEDAW), and other relevant frameworks in their extension programmes.

Build the evidence base by gathering and analysing information around the social and gender dimensions of climate change, and by developing adequate methodologies for measuring the gender impacts of climate change at local, national and international levels.

\section{References}

Acquah H. D. (2011) Public Awareness and Quality of Knowledge Regarding Climate Change in Ghana: A logistic Regression Approach. Journal of Sustainable Development in Africa 13(3) 146-157

Bord R Y; Fisher A \& O'Connor R E. (1998) Public Perceptions of Global Warming: United States and International Perspectives. Climate Research Vol $1175-84$

Brody S D; Zahran S; Vedlitz A \& Grover H (2008) Examining the Relationship Between Physical Vulnerability and Global Climate Change in the United States. Environment and Behaviour 40 (1): 71-95

Care (n.d) The Human Face of Climate Change. [Online] Available www.careclimatechange.org (July 3, 2013)

pDFID (2011) Climate and Environmental Advisers Competency Framework. [Online] Available: https://www.gov.uk/.../limate-andenvironment-advisers-competency (July 2, 2013.)

Ekpo I. U. \& Ekpo I. J. (2011) Assessing the Level of Climate Change Awareness Among Secodary School Teachers in Calabar Municipality, Nigeria: Implication for Management. International Journal of Humanity and Social Science. 1 (3) 106-110

European Commission (2011) Special Eurobarometer 372 "Climate Change" [Online] Available http:/lec.europa.eu/public_opinion lindex_en.htm (July 3,2013$)$

Henry, A. D. (2000). Public perceptions of global warming. Human Ecology Review, 7(1), 25-30.

Jekayinfa, A. A. and Yusuf, A .(2012) Creating Climate Change Awareness on the Nigerian Citizens: Challenges for Social Studies Curriculum Planners and Implementors. Edited Proceedings of the University of llorin and University of Cape Coast Joint International Conference on Climate Change and Sustainable Development

Kollmuss, A. A. and Agyeman, J. (2002) Mind the Gap: why do people act environmentally and what are the barriers to proenvironmental behaviour. Environmental Education Research 8 (3) 239-260

Leiserowit, A. (2006) Climate Change Risk Perception and Policy Preferences: The Role of Affect, Imagery and Values. Climatic Change: 77 : 45-72

Moench, M (2011) Aren't we all vulnerable: Why do vulnerability analysis? I I E D Opinion Lesson from Adaptation in Practice. London: I IED.

Otto-Banaszak I; Matczaki, P; Wsscler J \& Wechsung F (2010) Different Perceptions of Adaptation to Climate Change: a mental model approach applied to the evidence from expert interviewees. Regional Environmental Change. DOI 10.1007/s10113-010-0144-2

Pande H. T. and Raut, A. (2011) Assessment of Awareness Regarding Climate Change and its Health Hazards among Medical Students. Indian Journal of Occupation and Environmental Medicine. 15(1): $42-45$

ProAct Network (2008) The Role of Environmental Management and Eco-Engineering in Disater Risk Reduction and Climate Adaptation. Finland: Ministry of Environment

Saroar, M and Routray, J. K. (2010) Why does Climate Awareness Differ? Lesson Learned from Bangladesh. Paper presented at $2^{\text {nd }}$ International Conference: Climate, Sustainability and Development in Semi-arid Regions. August 16-20, 2010 Forteleza-Ceara, Brazil.

Skinner E. (2011) Gender and Climate Report. Brighton: BRIDGE/ Instutute of Development Studies.

Slovic, P. (2000). Rational actors and rational fools: The influence of affect on judgment and decision making. Roger Williams University Law Review, 6(1), 163-212. 
South East Climate Consortium (2009) Extension and the Climate Change Challenge: Providing Climate to Citizens and Communities. [Available] Online www.seclime.org (July 3, 2013)

Sussman F. G. and Freed J. R. (2008) Adapting to Climate Change: A Business Approach. Arlington: Pew Centre on Global Climate Change.

UNESCO (2010) Climate Change Initiative. Document SC-10/CONF.201/INF.6. [Online] Available http://portal.unesco.org/science/en lev.php-URL id=6793_. (March 4, 2013) 